\title{
I PLAY AT WORK - ten principles for transforming work processes through gamification
}

\author{
Florin Oprescu $^{1 *}$, Christian Jones ${ }^{2}$ and Mary Katsikitis ${ }^{2}$ \\ ${ }^{1}$ Faculty of Science, Health, Education and Engineering, School of Health and Sport Sciences, University of the Sunshine Coast, Sippy Downs, QLD, Australia \\ ${ }^{2}$ Faculty of Arts and Business, University of the Sunshine Coast, Sippy Downs, QLD, Australia
}

\author{
Edited by: \\ Natasha Kirkham, Birkbeck College, \\ UK

\section{Reviewed by:} \\ Jennifer A. Robinson, Royal \\ Melbourne Institute of Technology, \\ Australia \\ Ingrid Richardson, Murdoch \\ University, Australia

\section{*Correspondence:} \\ Florin Oprescu, Faculty of Science, \\ Health, Education and Engineering \\ School of Health and Sport \\ Sciences, University of the Sunshine \\ Coast, Locked Bag 4, Maroochydore \\ DC QLD 4558, Australia \\ e-mail: foprescu@usc.edu.au
}

Gamified workplaces could be a positive and innovative solution to addressing contemporary problems in organizations. Such problems include high levels of stress, reduced sense of community, reduced loyalty and rapid changes in the workforce. To better prepare organizations for the future it may be helpful to identify and understand the potential advantages, disadvantages and areas for future research in relationship to the use of gamification for personal and organizational wellbeing. An analysis of research literature across disciplines in combination with expert opinion identified gamified workplaces as a promising strategy for promoting wellbeing. Furthermore, this paper proposes a set of 10 principles (I PLAY AT WORK) that may support gamification efforts. In addition to the value of mapping the present for the benefit of the future, there is also considerable value in reshaping core ideas related to the workplaces. Gamified workplaces can provide opportunities for a more vigorous and strategic inter-disciplinary research agenda that can stimulate investments in the area.

Keywords: gamification, gamified workplaces, gamified systems, redesign of work processes, organizational and personal wellbeing, play, wellbeing

\section{INTRODUCTION}

Recently it was proposed that gamified services will become a key element in marketing and customer retention initiatives (Dorling and McCaffery, 2012). We are proposing that gamified workplaces will become a key element in the recruitment and retention of a productive and healthy workforce. This is because using gamified systems in the workplace could be a positive and innovative solution to addressing contemporary issues in organizations. Such issues include high levels of stress (Perryer et al., 2012), reduced social capital (Zhu et al., 2013), reduced loyalty and rapid changes in the workforce demographics (Dorling and McCaffery, 2012). From a health perspective, organizations will be likely to face an increased prevalence of stress, overweight and obesity in the workforce with a direct and indirect impact on ailments such as cardiovascular disease, diabetes and even addictions (Bosworth, 2012). To better prepare organizations for the future it may be helpful to consider the question: "What gaming principles could be used to gamify work places and processes so that both the employee and the employer benefit in terms of productivity and wellbeing?" In order to attempt to answer this question we will first discuss gamified workplaces, gamification, and gamification research.

Gamified workplaces are not workplaces where employees play videogames (Lewis, 2007; Farrington, 2011; Landers and Callan, 2011; Connolly et al., 2012; Popescu et al., 2012, 2013). Gamified workplaces can be defined as organizations that use gamification to transform some of their work processes into a game-like experience for the employees by applying selected principles of game design and game interaction. The long term goal of a gamified workplace is to increase wellbeing at the organizational level (i.e., productivity) and personal level (i.e., work satisfaction).
Gamification is a concept that garners increasing attention across funding bodies, academic disciplines and various industries (Dorling and McCaffery, 2012). For the purpose of this paper workplace gamification is defined as the adaptation and application of game design principles and game interaction elements to workplace processes and behaviors. Game interaction elements include both game mechanics and game dynamics. Game mechanics refer to the reward systems and game dynamics refer to the user progression that may lead to the rewards (Dorling and McCaffery, 2012).

Gamification research is still in its infancy and the transition from games to gamification remains a work in progress as documented by recent publications (Deterding et al., 2011; Koutropoulos, 2012; Dominguez et al., 2013; Rednic et al., 2013). In the literature, "gamification" has been described as the use of video-game elements to improve user engagement and experience with non-game initiatives (Deterding et al., 2011; Dominguez et al., 2013; Rednic et al., 2013). Hypothesized benefits include more engaging workplaces and additional opportunities for productive collaboration (Deterding et al., 2011; Rednic et al., 2013), increased motivation (Koutropoulos, 2012; Dominguez et al., 2013) and work place customization for enhanced personal control (Rednic et al., 2013).

There are many types of games applicable to workplaces. Games can be used for recruitment and training purposes (i.e., military), for lead generation, recruitment and public relations (i.e., Intelligence agencies), for selection (i.e., problem based interviewing), for training, continuous professional development and up skilling of the workforce (i.e., health professions), for planning, performance and review processes (i.e., public sector), 
for skill based promotion (i.e., engineering), and for development of personal health skills (i.e., Keas) among others. Crookall (2010) provided a list of disciplines using games and publication outlets for games and identified some of the research development needs in the field.

\section{PLAY AT WORK-10 PRINCIPLES FOR WORKPLACE GAMIFICATION}

In response to the needs identified in previous research this section proposes 10 guiding principles that may facilitate the adoption and use of gamification in everyday workplace processes and not just in training or special engagement events. Such principles could be used to make workplace processes more appealing for employees and more value generating for employers. This is because, from a psychological perspective, gamified workplaces could be seen as self-improving, self-learning entities where behavior change is created and sustained (Baranowski et al., 2011).

The ten principles proposed for gamifying work processes have been organized under the mnemonic I PLAY AT WORK.

\begin{tabular}{lll}
\hline ID & Principle & Description \\
\hline 1. & I Orientation & $\begin{array}{l}\text { Gamified processes place the } \\
\text { user (employee) at the center of } \\
\text { the experience }\end{array}$ \\
&
\end{tabular}

2. Persuasive elements

Gamified processes include persuasive elements based on sound psychological and behavioral theories

\begin{tabular}{|c|c|c|c|c|}
\hline 3. & Learning orientation & $\begin{array}{l}\text { Focus on knowledge } \\
\text { acquisition, skill development, } \\
\text { motivational outcomes or } \\
\text { behavior change }\end{array}$ & $\begin{array}{l}\text { Theory of planned behavior, } \\
\text { self-efficacy, experiential learning }\end{array}$ & $\begin{array}{l}\text { Development of personal and } \\
\text { organizational capabilities and } \\
\text { resources }\end{array}$ \\
\hline 4. & Achievement based rewards & $\begin{array}{l}\text { Focus on a justifiable and } \\
\text { predictable return on } \\
\text { investment }\end{array}$ & $\begin{array}{l}\text { Theory of planned behavior, } \\
\text { experiential learning }\end{array}$ & $\begin{array}{l}\text { Increased personal satisfaction } \\
\text { and employee retention }\end{array}$ \\
\hline 5. & Y Generation adaptable & $\begin{array}{l}\text { Generation } Y \text { is the fastest } \\
\text { growing segment of the } \\
\text { workforce and they are looking } \\
\text { for work experiences that are } \\
\text { supportive, fun and engaging }\end{array}$ & $\begin{array}{l}\text { Hierarchy of needs, psychogenic } \\
\text { needs }\end{array}$ & $\begin{array}{l}\text { Employee acquisition and } \\
\text { retention }\end{array}$ \\
\hline 6. & Amusement factors & $\begin{array}{l}\text { Inclusion of humor, play and fun } \\
\text { elements as part of the work } \\
\text { processes }\end{array}$ & $\begin{array}{l}\text { Psychogenic needs, social learning } \\
\text { theory }\end{array}$ & $\begin{array}{l}\text { Increased personal satisfaction } \\
\text { and enhanced wellbeing }\end{array}$ \\
\hline 7. & Transformative & $\begin{array}{l}\text { Use of a balanced and attractive } \\
\text { combination of competition and } \\
\text { collaboration in order to } \\
\text { transform existing work } \\
\text { processes within an } \\
\text { organization }\end{array}$ & Leadership theories, team building & Enhanced productivity \\
\hline 8. & Wellbeing oriented & $\begin{array}{l}\text { Focus on personal and } \\
\text { organizational wellbeing }\end{array}$ & $\begin{array}{l}\text { Organizational behavior, } \\
\text { self-competence }\end{array}$ & $\begin{array}{l}\text { Enhanced personal and } \\
\text { organizational wellbeing }\end{array}$ \\
\hline 9. & Research generating & $\begin{array}{l}\text { Collaborative research efforts } \\
\text { must be encouraged to justify } \\
\text { future investments in the area }\end{array}$ & $\begin{array}{l}\text { Organizational needs assessment } \\
\text { and evaluation }\end{array}$ & $\begin{array}{l}\text { Enhanced monitoring and } \\
\text { decision making }\end{array}$ \\
\hline 10. & Knowledge-based & $\begin{array}{l}\text { Based on knowledge, either as } \\
\text { an outcome or as feedback }\end{array}$ & $\begin{array}{l}\text { Organizational training, adult } \\
\text { learning }\end{array}$ & $\begin{array}{l}\text { Development of personal and } \\
\text { organizational capabilities and } \\
\text { resources }\end{array}$ \\
\hline
\end{tabular}

\section{Theoretical basis}

Operant conditioning, locus of control, self-efficacy

Theory of planned behavior, stages of change theory, uncertainty management

Theory of planned behavior, acquisition, skill development, motivational outcomes or Focus on a justifiable and predictable return on

Generation $Y$ is the fastest growing segment of the or work experiences that are

Inclusion of humor, play and fun elements as part of the work Use of a balanced and attractive combination of competition and order to processes within an Focus on personal and Collaborative research efforts must be encouraged to justify Based on knowledge, either as an outcome or as feedback

\section{Expected benefits}

Increased engagement, sense of control and self-efficacy

Adoption of new initiatives Increased satisfaction with internal communication

Development of personal and organizational capabilities and 
The aforementioned will be described next in conjunction with the supporting literature.

\section{ORIENTATION}

Successful games engage the users by focusing on cognitive, emotional, and social outcomes (Dominguez et al., 2013). Successful games include personally relevant, carefully designed and increasingly difficult challenges, often interspersed with humorous elements (Coller and Scott, 2009). Such challenges require increased cognitive effort, skill development and contributions from the users.

In the same way that games encourage users to progress through various levels, gamified work processes may encourage users to progress through increasingly difficult tasks (Deterding et al., 2011; Barthel, 2013; Popescu et al., 2013), may increase participation in special initiatives (Papastergiou, 2009; Barthel, 2013) may increase adoption of new programs (Lu et al., 2012; Rednic et al., 2013), and may increase program use period (Coller and Scott, 2009; Kato, 2010; Lu et al., 2012).

An interdisciplinary approach to system design is recommended for best results (Brox et al., 2011; Ahola et al., 2013). It is recommended to use a user-centered philosophy as a basis for process and system design (Brox et al., 2011; Bosworth, 2012; Cafazzo et al., 2012). For example, each user, in consultation with colleagues and managers, could set concrete goals and concrete standards of success or failure (Brox et al., 2011; Barthel, 2013). Such an approach may allow for various work processes to be tailored to a specific audience (Baranowski et al., 2012; Ahola et al., 2013; Barthel, 2013) while allowing for personalization based on individual preferences (Barreneche, 2012).

\section{PERSUASIVE ELEMENTS}

Inclusion of persuasive elements based on sound psychological and behavioral theories may encourage participants to want to explore and learn more in ways that are beneficial to both the user and the company (Michaelides, 2011; Barreneche, 2012; Barthel, 2013). For example, the use of persuasive elements in communication and delivery of new initiatives could enhance lead generation and participant acquisition (Barreneche, 2012; Lease and Yilmaz, 2013).

An example is Google. At a very high level Google is using gamification principles to influence adult behavior (Barreneche, 2012). Through game like elements Google incentivizes users to contribute data (i.e., reviews and corrections), to change behavior (i.e., selection of a restaurant) or to have them pay for services (Google Ads). It also uses continuous passive and active push and pull of data to/from users. In this way, Google uses the benefits of crowdsourcing inherent in gamification to collect data in automated and non-automated ways (Lease and Yilmaz, 2013) with a focus on continuous learning and resource development.

\section{LEARNING ORIENTATION}

An extensive review of games and their potential positive impact on learning is available elsewhere (Connolly et al., 2012). Some key benefits noted were knowledge acquisition, skill (motor, cognitive, social, and emotional) development, motivational outcomes and behavior change (Connolly et al., 2012). Gamification can support learning through immediate or delayed feedback (Crookall, 2010; Perryer et al., 2012; Popescu et al., 2012), resulting in increased self-efficacy (Papastergiou, 2009; Lu et al., 2012; Perryer et al., 2012; Popescu et al., 2013) and healthy behavior change (Kato, 2010; Lenihan, 2012; Kharrazi et al., 2012) Gamified work process design may be most successful if it is informed by psychological and health behavior theories (Brox et al., 2011; Baranowski et al., 2012), including those focused on rewards.

\section{ACHIEVEMENT BASED REWARDS}

The use of virtual or real rewards has been shown to increase adoption of new initiatives (Perryer et al., 2012; Whitton, 2012; Dominguez et al., 2013). Achievement based rewards could also help build relationships between employees and stronger loyalty to the company if gamified systems and programs are perceived by employees as wellbeing oriented perks (Perryer et al., 2012; Dominguez et al., 2013), For example, a gamified process focuses on positive feedback as a form of virtual reward and as a way to increase self-efficacy (Papastergiou, 2009; Kark, 2011; Lu et al., 2012; Perryer et al., 2012). This is because the employees may expect a justifiable and predictable return on their investment (Bosworth, 2012).

\section{Y-GENERATION ADAPTABLE}

New employees, especially the Y generation, may find a gamified workplace more attractive because they value work experiences that are supportive, fun, engaging and rewarding (Bosworth, 2012). Y generation individuals want to express their opinions, want to try out different personalities in a safe environment and want to be rewarded often (even if only virtually). The combination of human computer interaction and gamification may have an important impact on the engagement, loyalty and productivity of this group. Due to their familiarity with technology the self-efficacy and social capital of Y generation individuals can be achieved through both virtual and physical rewards (Barreneche, 2012). Rewards can include access to additional informational support and elements of fun (Brox et al., 2011; Bosworth, 2012).

\section{AMUSEMENT FACTORS (FUN ELEMENTS)}

Workplace activities can be made more attractive through the introduction of elements of fun (Coller and Scott, 2009; Crookall, 2010; Deterding et al., 2011; Michaelides, 2011; Gomes et al., 2012). A fun environment could be achieved by focusing on a balance between collaboration and competition oriented activities (Fernandes et al., 2012; Gomes et al., 2012). Such programs can result in improved morale, productivity and health behaviors (Bosworth, 2012; Gomes et al., 2012) with the long term outcome of a healthier partnership between employers and employees, a partnership which may result in both individual and organizational benefits.

\section{TRANSFORMATIVE}

A gamified system can use a balanced and attractive combination of competition and collaboration in order to transform existing work processes within an organization (Bosworth, 2012; Gomes et al., 2012; Perryer et al., 2012). For example, a gamified work process may allow employees to adopt a new persona, even if 
only for a limited time. Such a persona can be a different position than their usual one (i.e., Environmental Scientist instead of Project manager) (Fennewald and Kievit-Kylar, 2012). A gamified process could integrate professionalism and moral decisions into the mix in order to enhance the desired skills of the participants (Coller and Scott, 2009). In the short term, the goal of a gamified workplace may be to train employees in new work processes. Medium term goals may be to enhance productivity. The long term goal may be to foster employee and organizational wellbeing.

\section{WELLBEING-ORIENTED}

It has been documented that gamified systems could improve health and productivity while reducing health care related costs (Bosworth, 2012; Ferguson, 2012; Gomes et al., 2012; Lenihan, 2012).

The focus of a gamified system must be on the users' psychosocial experience and wellbeing (Gomes et al., 2012). In regards to psychosocial experiences it is important to recognize that adults have a greater need to document their memories, connections and reactions, thus they can become co-creators of the gamified workplace with the help of modern technology (Barreneche, 2012). This can be particularly powerful for social capital development.

Furthermore, gamification could contribute to the wellbeing of employees and to the wellbeing of management (Kark, 2011). For example, games can be used within an organization for the professional development of managers who could make decisions and identify the consequences of those decisions in a safe environment through simulation and role-play (Kark, 2011).

\section{RESEARCH-GENERATING}

Designing, implementing and evaluating a gamified system is a complex task (Brox et al., 2011). For an organization to consider gamifying its work processes, it needs a clear understanding of the potential benefits through research. Gamified systems could transform work related processes at multiple levels including the development of a research oriented culture. Gamified workplaces could allow researchers, managers and employees to collaborate in order to better understand the changes required in their work (Barreneche, 2012). Furthermore, human computer interaction research and practice could contribute to and could benefit a great deal from the gamified workplace in both small and large organizational settings (Gomes et al., 2012).

\section{KNOWLEDGE-BASED}

Finally, gamified processes must be based on knowledge, either as an outcome or as feedback. Successful games have short, medium, and long term goals (Dorling and McCaffery, 2012). The goals of a game are often clear and easy to monitor (Coller and Scott, 2009). In a gamified process some key goals could be setup in a clear manner. Such goals must encourage some level of risk taking, yet the options or leverages available to the employee could be limited to a predetermined set (Farhangi, 2012) such as workplace regulations and policies. Systematic feedback, including rewards, could be used to generate desired behavioral changes.

For example, a gamified process would provide immediate feedback and allow for immediate progression if the employees measurable results meet a given threshold. Furthermore, gamified processes could provide multiple types of feedback such that the employee has incentives to return and practice until they reach the maximum level of achievement possible on each task or combination of tasks (Dorling and McCaffery, 2012), thus placing the employee at the center of the gamified process (I orientation).

\section{FUTURE DIRECTIONS}

The I PLAY AT WORK principles could be used in the future to foster and study productivity in the gamified workplace, health promotion in the gamified workplace, psychological benefits of the gamified workplace and human computer interaction in the gamified workplace. Productivity is one of the key measurements that management is interested in and thus should come first (Kark, 2011). Second, preventative health care can play a major role in reducing the direct and indirect costs of illness in the workforce. Some authors estimate that more than two trillion dollars could be saved in the US alone if prevention is given appropriate attention (Bosworth, 2012). The most promising directions at the moment are gamified systems which include social elements. They seem to work best on widely accepted health behaviors such as weight loss through better nutrition and increased physical activity. However there is limited information on gamified initiatives that focus on less accepted behavior such as alcohol misuse or less understood health conditions such as mental health and illness. It is in this area that psychological research could make a great contribution. Simply put, happy people may be more productive people.

I PLAY AT WORK principles are a work in progress. However, we do hope that they will be useful in generating direction, discussion, and development in relationship to the gamified workplace.

\section{CONCLUSION}

We are still in the early stages of understanding how gamification can be best used in the workplace for positive behavior change. An analysis of research literature across disciplines identified an emerging base of evidence that suggests gamification as a promising strategy for promoting loyalty, productivity, and wellbeing in the workplace. However there are many gray areas left to address in the near future, such as how to practically and easily measure the value of the gamified workplace for personal and organizational wellbeing. In addition to the value of mapping the present for the benefit of the future, there is also considerable value in reshaping core ideas related to the workplaces. Gamified workplaces can provide opportunities for a more vigorous and strategic inter-disciplinary research agenda that can stimulate investments in the area.

\section{REFERENCES}

Ahola, R., Pyky, R., Jämsä, T., Mäntysaari, M., Koskimäki, H., Ikäheimo, T. M. et al. (2013). Gamified physical activation of young men-a multidisciplinary population-based randomized controlled trial (MOPO study). BMC Public Health 13, 32. doi: 10.1186/1471-2458-13-32

Baranowski, T., Baranowski, J., O'Connor, T., Lu, A. S., and Thompson, D. (2012) Is enhanced physical activity possible using active videogames? Games Health Res. Dev. Clin. Appl. 1, 228-232. doi: 10.1089/g4h.2012.0018 
Baranowski, T., Baranowski, J., Thompson, D., and Buday, R., (2011). Behavioral science in video games for children's diet and physical activity change: key research needs. J. Diabetes Sci. Technol. 5, 229-233. doi: 10.1177/193229681100500204

Barreneche, C. (2012). Governing the geocoded world: environmentality and the politics of location platforms. Convergence 18, 331-351. doi: $10.1177 / 1354856512442764$

Barthel, M. L. (2013). President for a day: video games as youth civic education. Inform. Commun. Soc. 16, 28-42. doi: 10.1080/1369118X.2011.627176

Bosworth, A. (2012). Keas: developing a successful game-based employee wellness program. Games Health Res. Dev. Clin. Appl. 1, 189-191. doi: 10.1089/g4h.2012.0020

Brox, E., Fernandez-Luque, L., and Tøllefsen, T. (2011). Healthy gamingvideo game design to promote health. Appl. Clin. Inform. 2, 128-142. doi: 10.4338/ACI-2010-10-R-0060

Cafazzo, J. A., Casselman, M., Hamming, N., Katzman, D. K., and Palmert, M. R. (2012). Design of an mHealth app for the self-management of adolescent type 1 diabetes: a pilot study. J. Med. Internet Res. 14, e70. doi: 10.2196/jmir.2058

Coller, B. D., and Scott, M. J. (2009). Effectiveness of using a video game to teach a course in mechanical engineering. Comput. Educ. 53, 900-912. doi: 10.1016/j.compedu.2009.05.012

Connolly, T. M., Boyle, E. A., MacArthur, E., Hainey, T., and Boyle, J. (2012). A systematic literature review of empirical evidence on computer games and serious games. Comput. Educ. 59, 661-686. doi: 10.1016/j.compedu.2012.03.004

Crookall, D. (2010). Serious games, debriefing, and simulation/gaming as a discipline. Simul. Gaming 41, 898-920. doi: 10.1177/1046878110390784

Deterding, S., Sicart, M., Nacke, L., O'Hara, K., and Dixon, D. (2011). "Gamification. using game-design elements in non-gaming contexts," in Proceedings of the 2011 Annual Conference Extended Abstracts on Human Factors in Computing Systems, 2425-2428. doi: 10.1145/1979742.1979575

Dominguez, A., Saenz-de-Navarrete, J., De-Marcos, L., Fernández-Sanz, L., Pagés, C., and Martinez-Herráiz, J.-J. (2013). Gamifying learning experiences: practical implications and outcomes. Comput. Educ. 63, 380-392. doi: 10.1016/j.compedu.2012.12.020

Dorling, A., and McCaffery, F. (2012). The gamification of SPICE. Softw. Process Improv. Capability Determ. 290, 295-301. doi: 10.1007/978-3-642-30439-2_35

Farhangi, S. (2012). Reality is broken to be rebuilt: how a gamer's mindset can show science educators new ways of contribution to science and world? Cult. Stud. Sci. Educ. 7, 1037-1044. doi: 10.1007/s11422-012-9426-y

Farrington, J. (2011). From the research: myths worth dispelling: seriously, the game is up. Performance Improv. Q. 24, 105-110. doi: 10.1002/piq.20114

Fennewald, T. J., and Kievit-Kylar, B. (2012). Integrating climate change mechanics into a common pool resource game. Simul. Gaming. doi: 10.1177/ 1046878112467618. Available online at: http://sag.sagepub.com/content/ early/2012/12/12/1046878112467618.full.pdf

Ferguson, B. (2012). Games for wellness-impacting the lives of employees and the profits of employers. Games Health Res. Dev. Clin. Appl. 1, 177-179. doi: 10.1089/g4h.2012.0023

Fernandes, J., Duarte, D., Ribeiro, C., Farinha, C., Pereira, J. M., and Silva, M. M. (2012). iThink: a game-based approach towards improving collaboration and participation in requirement elicitation. Procedia Comput. Sci. 15, 66-77. doi: 10.1016/j.procs.2012.10.059

Gomes, N., Merugu, D., O’Brien, G., Mandayam, C., Yue, J. S., Atikoglu, B., et al. (2012). "Steptacular: an incentive mechanism for promoting wellness," in Communication Systems and Networks (COMSNETS), 2012 Fourth International Conference (Bangalore), 1-6.

Kark, R. (2011). Games managers play: play as a form of leadership development. Acad. Manag. Learn. Educ. 10, 507-527. doi: 10.5465/amle.2010.0048

Kato, P. M. (2010). Video games in health care: closing the gap. Rev. General Psychol. 14, 113-121. doi: 10.1037/a0019441

Kharrazi, H., Lu, A. S., Gharghabi, F., and Coleman, W. (2012). A scoping review of health game research: past, present, and future. Games Health Res. Dev. Clin. Appl. 1, 153-164. doi: 10.1089/g4h.2012.0011
Koutropoulos, A. (2012). Academic check-ins: mobile gamification for increasing motivation. Instr. Technol. 9, 3-20. Available online at: http://www.itdl.org/ Journal/May_12.pdf\#page=7

Landers, R. N., and Callan, R. C. (2011). "Casual social games as serious games: the psychology of gamification in undergraduate education and employee training," in Serious Games and Edutainment Applications, eds. M. Ma, A. Oikonomou, and L. C. Jain (Surrey: Springer), 399-423.

Lease, M., and Yilmaz, E. (2013). Crowdsourcing for information retrieval: introduction to the special issue. Inf. Retrieval, 16, 1-10. doi: 10.1007/s10791-0139222-7

Lenihan, D. (2012). Health games: a key component for the evolution of wellness programs. Games Health Res. Dev. Clin. Appl. 1, 233-235. doi: 10.1089/g4h.2012.0022

Lewis, M. W. (2007). Analysis of the roles of "serious games" in helping teach health-related knowledge and skills and in changing behavior. J. Diabetes Sci. Technol. 1, 918-920. doi: 10.1177/193229680700100618

Lu, A. S., Baranowski, T., Thompson, D., and Buday, R. (2012). Story immersion of videogames for youth health promotion: a review of literature. Games Health Res. Dev. Clin. Appl. 1, 199-204. doi: 10.1089/g4h.2011.0012

Michaelides, D. (2011). Will gamify those processes. The art of innovation in the public sector. Int. J. Innov. Sci., 3, 117-126. doi: 10.1260/1757-2223. 3.3.117

Papastergiou, M. (2009). Exploring the potential of computer and video games for health and physical education: a literature review. Comput. Educ. 53, 603-622. doi: 10.1016/j.compedu.2009.04.001

Perryer, C., Scott-Ladd, B., and Leighton, C. (2012). Gamification: implications for workplace intrinsic motivation in the 21st century. AFBE J. 371-381. Available online at: http://www.afbe.biz/main/wp-content/uploads/ AFBEJournal-SpecialIssue2012.pdf\#page $=134$

Popescu, M., Romero, M., and Usart, M. (2012). Using serious games in adult education serious business for serious people-the MetaVals game case study. ICVL 2012-7th International Conference on Virtual Learning (Bucharest) 125-134.

Popescu, M. M., Romero, M., and Usart, M. (2013). Serious games for serious learning using SG for business, management and defence education. Int. J. Comput. Sci. Res. Appl. 3, 5-15. Available online at: http://www.ijcsra.org/ current-issue/v3il

Rednic, E., Toma, A., and Apostu, A. (2013). "Organize distributed work environments in a game-like fashion," in Recent Advances in Knowledge Engineering and Systems Science, eds Z. Chen and E. Lopez-Neri (Cambridge: WSEAS Press), 213-218.

Whitton, N. (2012). The place of game-based learning in an age of austerity. Electron. J. e-Learn. 10, 249-256. Avilable online at: http://www.ejel.org/issue/ download.html?idArticle $=197$

Zhu, M., Huang, Y., and Contractor, N. S. (2013). Motivations for self-assembling into project teams. Soc. Netw. 35, 251-264. doi: 10.1016/j.socnet.2013.03.001

Conflict of Interest Statement: The authors declare that the research was conducted in the absence of any commercial or financial relationships that could be construed as a potential conflict of interest.

Received: 01 May 2013; accepted: 07 January 2014; published online: 30 January 2014. Citation: Oprescu F, Jones C and Katsikitis M (2014) I PLAY AT WORK-ten principles for transforming work processes through gamification. Front. Psychol. 5:14. doi: 10.3389/fpsyg.2014.00014

This article was submitted to Developmental Psychology, a section of the journal Frontiers in Psychology.

Copyright (c) 2014 Oprescu, Jones and Katsikitis. This is an open-access article distributed under the terms of the Creative Commons Attribution License (CC BY). The use, distribution or reproduction in other forums is permitted, provided the original author(s) or licensor are credited and that the original publication in this journal is cited, in accordance with accepted academic practice. No use, distribution or reproduction is permitted which does not comply with these terms. 